\title{
Article
}

\section{Literacy practices in the learning careers of childcare students}

Smith, June, Satchwell, Candice, Edwards, Richard, Fowler, Zoe, Gaechter, Joyce, Knowles, Joanne, Phillipson, Christine and Young, Rosheen

Available at https://clok.uclan.ac.uk/7247/

Smith, June, Satchwell, Candice orcid iconORCID: 0000-0001-8111-818X, Edwards, Richard, Fowler, Zoe, Gaechter, Joyce, Knowles, Joanne, Phillipson, Christine and Young, Rosheen (2009) Literacy practices in the learning careers of childcare students. Journal of Vocational Education and Training, 60 (4). pp. 363-375. ISSN 1363-6820

It is advisable to refer to the publisher's version if you intend to cite from the work. http://dx.doi.org/10.1080/13636820802591764

For more information about UCLan's research in this area go to http://www.uclan.ac.uk/researchgroups/ and search for <name of research Group>.

For information about Research generally at UCLan please go to http://www.uclan.ac.uk/research/

All outputs in CLoK are protected by Intellectual Property Rights law, including Copyright law. Copyright, IPR and Moral Rights for the works on this site are retained by the individual authors and/or other copyright owners. Terms and conditions for use of this material are defined in the policies page.

\section{CLoK}

Central Lancashire online Knowledge www.clok.uclan.ac.uk

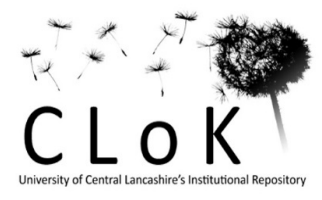




\section{Literacy practices in the learning careers of childcare students}

June Smith (a), Candice Satchwell (b), Richard Edwards (a) and Zoe Fowler (b); with

Joyce Gaechter (c), Joanne Knowles (d), Kate Miller (a), Christine Phillipson (e) and Rosheen Young (f)

Contact:

Richard Edwards

Institute of Education

University of Stirling

Stirling

FK15 0HD

Email: r.g.edwards@stir.ac.uk

(a) University of Stirling

(b) Lancaster University

(c) Perth College

(d) Preston College

(e) Lancaster and Morecambe College

(f) Anniesland College 


\begin{abstract}
This paper draws from the Literacies for Learning in Further Education research project, funded through the Teaching and Learning Research Programme. Drawing on the empirical study of literacy practices in eight Childcare courses in Scotland and England, we seek to demonstrate that, integral to the learning careers of students are literacy careers through which their learning is mediated. In the process, by drawing upon the lens of literacy, we also challenge some of the common sense understandings of learning in childcare. In particular we suggest that the literacy practices of lower level courses can be more diverse than those of higher level courses, producing confusing literacy careers for the students involved. We also point to the complexity of the literacy careers in childcare, given that students are required to mediate different aspects of their experience through literacy. In particular there are the mediations made possible by the use of information technology and those entailed in relating work placements to classroom practice. We argue that students on vocational courses have complex literacy careers and that a literacies approach to learning helps to reveal this complexity.
\end{abstract}

Key words: Further Education, literacy practices, literacy careers, childcare, learning careers 


\section{Literacy practices in the learning careers of childcare students}

\section{Introduction}

The Literacies for Learning in Further Education research project (1)

(www.lancs.ac.uk/lflfe) was a three year study between 2004 and 2007, which sought to explore the literacy practices associated with learning in a number of curriculum areas in English and Scottish colleges. It also explored the everyday literacy practices of students of those subjects and the ways in which these could be drawn upon to enable them to learn more successfully. Part of the rationale for the project was to compare and contrast literacies for learning between the English and Scottish further education contexts, given the different policy and curriculum contexts. In order to do this, of the four curriculum areas studied within each of the four colleges with which the project worked, it was decided that we would research Childcare courses across the different settings. It is that aspect of the bigger project which is the focus of this article.

The macro-policy initiatives of both England and Scotland position Childcare and Early Years' Education courses as direct routes into the workplace. These courses are also meant to provide the potential for student progression into higher education. This is part of wider reforms in the labour market to career progression for those who begin working with children in less qualified positions. Further education Childcare courses can 
therefore fulfil a dual role. However, while there are similarities between England and Scotland in relation to overall policy, a major area of difference in further education is related to the meso-level, in particular in relation to awarding bodies and curriculum development.

In Scotland, the Scottish Qualifications Authority (SQA) is the sole, non-departmental, body responsible for the development, accreditation, assessment and certification of qualifications pertaining to Childcare. The introduction of the Scottish Credit and Qualifications Framework (SCQF) has led to the potential for clear progression for students to higher levels of study. All parties involved - employers, learners and further education staff - can track (in principle) which level of qualification leads to the next, how many credits each qualification has and how they relate one to the other.

In England, there is a separation between awarding bodies and curriculum development. While the Qualifications and Curriculum Authority (QCA) provides quality assurance for courses that receive further education funding, there is a plethora of awarding bodies who design, develop and verify qualifications. Consistency of levels is maintained across these qualifications through the regulatory criteria within the National Qualifications Framework $(\mathrm{NQF})$ which is managed by QCA. The QCA regulates and develops the curriculum, assessments, examinations and qualifications. But qualifications are granted by the different awarding bodies. An awarding body must gain recognised status from the QCA before it can propose qualifications for accreditation within the NQF. The 
complexity arising from the qualifications structure in England therefore differs from the more rationalised Scottish system.

The extent to which these differences have significant impact on pedagogic practices was part of our interest in conducting a direct comparison between the Scottish and English colleges in the area of Childcare. This paper therefore explores the literacy practices associated with learning Childcare subjects in further education. We seek to challenge some of the assumptions made around Childcare as a subject that have been highlighted by examining pedagogy through the lens of literacy. In particular, we seek to challenge assumptions that Childcare is an area which can be associated with limited literacy. We also highlight the amount of actual and potential mediation of different contexts college, home, and workplace - that is conducted through writing in these courses. In the process, we will expand the notion of learning careers that has been taken up in the study of further education in general (Bloomer 1997) and among Childcare students in particular (Colley, et al 2003) to embrace a notion of literacy careers. The concept of literacy career enables us to explore the ways in which students come to adopt certain forms of reading and writing as 'allowable' within their learning careers. Second, we explore the curriculum tension in the Childcare area that have emerged from attempting to put in place a career and qualifications structure that enables both preparation for the workplace and educational progression. Our aim then is to help illuminate certain issues and debates in the Childcare areas that have emerged from our study of literacy practices, but also to expand conceptually the notion of learning careers. We will also offer some observations on the comparisons between studying care in England and Scotland. 
While there has been much attention given to the literacy practices of young children (e.g. Gee 2003), particularly in relation to their interactions with digital technologies (Plowman and Stephen 2005), significantly less attention has been given to the literacy practices of those who work with children. It is the latter which is the focus of this paper. The article is in three parts. First, we provide the conceptual and methodological background on the LFLFE study. Second, we explore the key findings of the project in relation to Childcare as a subject, expanding on the points made above. Finally, we will indicate some of the possible implications of these findings.

\section{Background to the study}

Literacy is often seen as an autonomous value-free attribute lying within the individual a set of singular and transferable technical skills which can be taught, measured and tested at a level of competence. Such assumptions tend to result in individual deficit views of students' capacities to engage in and with reading and writing (Canning 2007). By contrast, the LfLFE project worked with the notion that literacies are not an abstracted set of skills that can be learnt in isolation from contexts of use, but are developed within meaningful and purposive activity. Thus our use of the term 'literacy practices' rather than literacy. We also viewed literacy practices broadly as embracing icon and screen as well as text and page, and the many multimodal artifacts and genres of communication which are to be found in colleges and everyday life, including the use of computers, mobile phones, etc (Kress 2003). The importance of recognizing the situated and contextspecific nature of literacy practices, how they are shaped by the institutional imperatives, 
epistemologies and cultural practices of the contexts in which they are located, has been demonstrated by work in the New Literacy Studies (Barton and Hamilton 1998, Barton, et al. 2000, Lankshear and Knobel 2003). This research has raised serious questions about the pedagogical integrity of teaching literacy as a set of isolated, transferable technical skills.

A situated view of literacy focuses on the meaningful and practical work people do through textual mediation. Specific forms of reading and writing are engaged with in the attempt to do things. Thus our focus was on literacies for learning rather than the learning of literacy. This situated view has also been used in the elaboration of the concept of learning careers in further education.

The concept of learning careers refers to the development of a student's dispositions to knowledge and learning over time. But that development is not to be understood simply as arising from the determined impact of enduring psychological traits upon dispositions. Rather, dispositions change as the result of the partly unpredictable influences of a variety of social and other factors, themselves mediated through horizons for action. (Bloomer 1997: 150, emphasis in original)

The concept of learning careers has developed in the attempt to provide a sociological understanding of the complex interactions between structure and agency, and past, present and future in the development of specific disposition to learning and knowledge. However, while situated learning theory (Lave and Wenger 1991) does engage with the 
discursive aspects of communities of practice, what is noticeable in its uptake in relation to further education is that it does not address the semiotic mediations of these sociological processes. Thus, while the cognitive and material aspects of learning are addressed in the concept of learning careers, the communicative dimensions are overlooked. In our project, therefore, exploring as it did learning through the lens of literacy practices, we started to posit that learning careers are also literacy careers, which develop dispositions toward certain forms of reading and writing in the textual mediation of learning.

To undertake this project, we adopted a collaborative ethnographic approach. To this end the four university-based researchers worked alongside sixteen further education practitioners (four in each of the four participating colleges). In each of the participating colleges, two Childcare units at two different levels were researched alongside the four Childcare tutors who acted as college-based researchers (Table 1). It was the intention of the project that the units chosen for the research would cover different levels of study, different student populations and different learning settings. However, the practicalities of working in the dynamic naturalistic settings of colleges meant that the final selection became focused more on full-time units and students than we would have liked. Only one of the units came from a part time programme. Across the four colleges, we looked at four units within the higher level of $\mathrm{HNC} /$ Level 3 and four units at the lower levels. Each unit consists of approximately 40 hours of learning and teaching.

Table 1 in here 
Within each unit, we also worked with four students to examine their literacy practices in and out of college. Where possible the students themselves became involved in the process as co-researchers and not simply respondents. However, it was recognized by the team that for many of the students, the use of the term 'co-researcher' to represent their involvement was more aspirational than evident from practice. Other than the three students who were on the Edexel National Certification in Early Years (level 3) programme in England, which was aimed at mature students, our student participants were learners aged 16-19 and on full time courses.

With one exception, the 32 students were female. Similarly, all of the Childcare tutors who worked with the project gathering data were also female. One college had a male head of provision for Childcare and there were male teachers in the departments from which Childcare operated. However, they were usually Social Science teachers or Science-based teachers who taught some aspects of the courses related to health. Colley et al (2003) found when studying further education that Childcare continues to be a feminized vocational area. It is not within the scope of this article to explore this aspect of Childcare provision, but we feel it is worthy of note that there has been a growing drive to improve the status, pay and conditions of those working with children. In three of the four colleges the programmes we studied were called 'Childcare and Education', but in Scotland during a later phase of the research, these course titles were changed to 'Early Education and Childcare'. This change in emphasis reflects a move to professionalize 
Childcare work by aligning it with the already professionalized area of Education. Over time, it will be interesting to see if that has any impact on the gendered employment patterns in this area.

Using a variety of interview, focus group, observational and visual approaches, we collected data on the multimodal literacy practices associated with the teaching, learning and assessment on each of the units and we explored the everyday literacy practices both within and outside the college of the random sample of students on each of those units. This data was subject to forms of descriptive and thematic analysis and the outcomes were explored in a one day workshop in which the university-based researchers and further education Childcare lecturers participated.

\section{Literacy Practices in Learning Childcare}

From the project, we have identified four categories of literacies for learning:

- literacies for learning to be a student e.g. registration, use of learning resource area

- literacies for learning to be a student of a particular subject, e.g. content focused learning

- literacies for assessment

- literacies for learning related to an imagined future e.g. placements, work simulations. 
In focusing on the Childcare curriculum, we will primarily be examining practices within the latter three of these (for information on the first, see Edwards and Smith 2005).

The project has also identified twelve dimensions to a literacy practice (see Table 2). A change in any aspect will change the nature of the practice, suggesting the complexity of the process of developing a literacy career, as it is not simply a linear accumulation of the skills of reading and writing, but an interplay of diverse and dynamic dimensions.

Table 2 in here

The textual mediation of learning Childcare, as with the other curriculum areas studied for the LfLFE project, presents a complex picture of practices and expectations. Tutors' choices of classroom material and assessments were influenced by the descriptors from which they were working, other forms of guidance from awarding bodies, the culture of college departments and the tutors' professional training and expectations, the perceived demands of the workplace and the anticipated practices of higher education. All of these were mediated through the judgment of the lecturer on the approach to be adopted in teaching specific topics in specific ways. As a result, a range of artifacts were used in teaching. Tutors used overhead transparencies (OHTs), PowerPoint presentations, information sheets, worksheets, magazines, leaflets, journals and handouts. In other words, a range of artifacts and practices were used in the pedagogic practices of Childcare, with their use arising out of a complex interplay of factors. Most relied on what we suggest are fairly traditional styles of pedagogic mediation. 
Students also produced a variety of texts: note taking from OHTs, completing worksheets, drawing spider grams, preparing presentations and wall displays, producing leaflets, advisory booklets, posters, writing menus for a whole week; researching topics using internet or books and designing game shows. Some literacy practices were taught explicitly, others were assumed. All were guided by the pedagogic approach adopted by the tutor.

Between the levels of programmes, there was a definite difference between the range of literacy practices with which students were expected to engage. Not only were there more practical exercises at the lower levels (which might be expected), but perhaps more surprisingly there was also a greater variety of literacy demands. The four tutors' reasons for adopting this variety were to engage the students in a positive way, to keep them interested in the subject and help them to integrate learning, assessment and the world of Childcare. In other words, the lower the level of unit the more diverse the literacy demands made upon students, while the higher the unit, the more narrowly focused the literacy demands. While variety was seen by the tutors as a motivating force for students, this did not address the complexities for the latter of developing the diverse literacy practices demanded of them. In terms of their literacy careers, there were inconsistent messages about what, in particular, the appropriate forms of writing were.

One such example was when a SCQF level 5 (English level 2) group were asked to produce (as an assessment) a handbook aimed at parents to help them understand their 
child's developmental stages between 0-5 years. The students' concerns centered around how to address this audience; how to get a professional finish so that it looked neat; the layout they would have to adopt and which images to use, if any. These were concerns about the practices around the production of a leaflet and in the end got in the way of them passing the assessment which required them to cover all the elements of the learning outcomes. In this particular case, all of the students had to remediate their assessment because aspects of the performance criteria had not been fulfilled. The students could not draw on their own literacy experiences as none of the group were parents; and did not come from a background of media production. In giving them something different and potentially engaging, the teacher had added a new dimension to the task of demonstrating knowledge as the students had to develop a new set of practices around the complex processes of leaflet production. It was thought that this was unproblematic, as they passed their basic skills assessments. This assumption about a literacy artifact was based on a skills based view of literacy that ignores the complex range of activities that surround the use and production of any form of text.

However, it was also noted that both students and staff enjoyed the experience of producing the leaflet because it was practical, they could work collaboratively; they could use pictures either drawn by themselves or taken from magazines, it was multi-modal and multi-media, non-linear and generative. As a learning activity, it had many benefits therefore. But because it was an assessment artifact the students had to meet the performance criteria. We would argue that there were too many purposes and too many audiences for this task to be successful as an assessment. The complexity of the form of 
assessment became the students' focus, rather than learning about the aspect of child development. This may well have been a legitimate learning experience if they would have to produce such a document when qualified or if every subsequent assessment required similar literacy practices. However, their teacher said that they would be unlikely ever to have to do this. What is significant here is the genre of writing for the assessment and its relationship to the course and future area of work. Writing a leaflet aimed at parents is a highly specialized literacy practice. While the teacher's intention may have been to make the assignment more interesting, it is not necessarily made more relevant by imposing a literacy demand which will not be useful in the workplace, nor if the student progresses simply to higher level courses.

This variety expected of lower level courses may mean that the courses can be more complex from a literacy perspective than higher level courses. In other words, their literacy careers are diverse and possibly fragmented, rather than focused on developing a narrower range of reading and writing. This challenges many common sense understandings. Students at the lower levels receive complex messages about what is necessary for them to do to succeed. At the lower levels, not only did students have to learn to develop literacy practices they would not need in the workplace, but these same practices would not be required at the higher levels of study either where the assessments students were likely to be asked to produce were one or at most two text-types across the programmes: essays and reports. We are not suggesting that teachers should only use relevant literacy practices, but if they do introduce new literacy practices, they do have to be aware of the additional requirements they are placing on their students. To help do 
this, we suggest that, as well as considering their students careers as learners, it would also be helpful for curriculum development and pedagogic practice to consider the development of the students' literacy careers and how these can best be scaffolded.

At the higher levels students received a more consistent message about appropriate forms of reading and writing, which relate to progressing to higher education. There is thus greater consistency in the literacy careers they are being required to develop. This is not to say that students at the higher levels had fewer literacy challenges. They faced different demands with an increased textualization of assessment based upon more extended reading and writing rather than work-related activities. Staff acknowledged that writing an essay would be difficult for students. As a result they organized classes on how to write essays at Induction, taught mainly by core/key skills teachers. The practice of teaching essay writing as a set of generic skills which can be transferred later is part of the autonomous view of literacy. This involves not only assumptions about student capabilities and the extent to which literacy practices are assumed to be transferable, but also whether tutors choose to use pedagogic strategies to develop those capabilities or work with the existing repertoires that students bring with them. The literacy demands of assessment were often additional to any literacy practices that students needed to develop within the workplace, as there was an anticipation of the demands to be faced by students in progressing educationally rather than entering the workplace.

For this project, we were interested in not only the ways in which learning could be developed within the context of the college classroom, but also the ways in which 
practices in that context could draw upon the practices in which students engaged in their everyday lives. When we investigated what students do in their daily lives, we discovered both a quantity and diversity of literacy practices in which they participated which far surpassed the expectations of the further education lecturers. When analyzed, the literacy practices which students tend to use in their everyday lives are, on the whole:

- multi-modal, i. e. combining symbols, pictures, colour, music

- multi-media, i.e. combining paper and electronic media

- shared, i.e. interactive, participatory and collaborative

- non-linear, i.e. with varied reading paths

- agentic, i.e. students having responsibility

- purposeful to the student

- having a clear audience

- generative

- self-determined in terms of activity, time and place

This contrasted with the narrower uses of artifacts utilized in pedagogic practices. This proved to be of particular significance in relation to the use of ICT. We found ICT to be a major means of engaging in literacy practices among the student participants. This included: mobile phones; computer and video gaming; msn and email; internet searching; teletext; music downloading and word-processing. Some of the characteristics that these literacy events shared were that they were collaborative, non-linear, self-determined, generative and multi-modal. Partly as a result of the way the concept of literacy is 
discussed in everyday life, and partly as a result of literacy being embedded in the activities, the project students were not aware that literacy was involved in these activities until they participated in the research. It is perhaps unsurprising that none of the teacher researchers were aware that their students engaged in such a wide and complex variety of practices in other areas of their lives either.

However, while at a national level, significant investment has been made into the ICT infrastructure of colleges, in the Childcare classrooms we explored, the students were provided with very few opportunities to engage with any use of ICT. There were statements in policy documents across all four colleges about the desire to increase the use of ICT in the classroom. Departmental managers spoke about their desire to enable this to happen and teachers spoke often of their desire to change their materials to incorporate ICT. However, when it came to actual classroom practice we found very little evidence of the impact of this. In the classrooms which were primarily for use in Childcare provision, there were no dedicated personal computers for students' use. Indeed in one college, PCs were brought into every classroom for an inspection visit but when the inspectors left, the computers were taken away. In a sense then, the learning environment was less rich from a literacy perspective than that often experienced by students in their everyday lives and also their prospective workplaces, especially when we take into account the huge growth of technological toys (Luckin et al 2003).

All four colleges had a Virtual Learning Environment (VLE), but where material had been provided for student use within Childcare, it was invariably presented exactly as it 
would be in a paper-based format or copies of OHTs were available on a CD. Reflecting on the VLE, one of the teacher researchers felt that if a student missed a session on this course the information was so complex that the student would still need the teacher's input, rather than be able to catch up by remotely accessing the resources. This reflects a view of ICT as merely another technological means of communicating with students, rather than a different multi-modal form of semiotic mediation.

This is not to say some tutors did not use ICT in the classroom. Where presentational facilities were available tutors did use them. Teachers used video material and PowerPoint presentations. However, where PowerPoint presentations were observed, this practice seemed to be very similar to the use of OHTs. Students would be presented with PowerPoint slides which had linear bulleted text. Additionally, the time pressures staff felt they were under meant that they were less likely to consider adopting new practices which might not work. If staff themselves do not model ICT with any regularity, then there are wider technological issues in relation to the use of other media and technological children's toys. Without these being freely available, how do students learn to use them with the next generation of children?

All four colleges had a central resource centre where a large number of PCs were available for students' use. But many of the students said they did not like to use the Learning Centres because there were too many distractions, they had to book machines in advance, they had to remember to bring a disk or USB pen drive and they had to 
remember their password. In a focus group interview at the end of their programme one of the students said she would prefer the computers to be in the classrooms:

'I think that would be actually really good because H. could say to me right I want you to start this assessment today, if we get it started then that means I can start typing it up right away and I don't have to go down to the [Learning Centre] I've got my own computer sitting there right there in front of me and no matter where I sit there would be a computer where I could log on and do the work whereas now you've got to go all the way down to the [Learning Centre] and book it and say how long you want it for and if you don't get it done then you've got to go and say can I have it for another hour.'

Because of this, many of them told us that when they had work that involved the use of PCs, where they were available at home, they preferred to work there. When students did use the Learning Centres it was for information gathering activity as an integral part of class time. Students would find the relevant sites and download lots of material to be read at home. At the higher levels, students did use PCs when they had extended texts to produce such as essays or reports; again this was more likely to be carried out at home. Most of them talked about a requirement to present this information as a word processed text. However, very few of the students created the text using a PC. Rather they handwrote the text and used the PC to make it look neat and check spelling. 
Drawing on multimodal literacy practices to mediate the everyday and classroom is one form of mediation in which care students are engaged. Another is the mediation of college learning and work placements. This is achieved through the maintenance of a logbook - a common artifact in further education courses in which there are work placements or simulations. The logbook is a central artifact in being a Childcare student. While all the students appreciated and valued the actual placement experience, writing the logbook was seen as a chore by many of the students, partly because it consisted of completing proformas. These logbooks differ in format across the qualification bodies but essentially are the same in purpose. Within the placement time, each student is expected to undertake a variety of tasks which cover the range of activities they would be expected to meet in a childcare setting. The logbooks are designed to capture this experience and to provide opportunities both to record what has taken place and to reflect on the student's development during placement. For many of the students recording of the activities presented few problems. However, the reflective element caused considerable challenges, as it consists in moving from a descriptive mode of writing to an analytical mode and is a particular genre of writing with which many students are unfamiliar.

In Scotland the logbook consisted of 50 planned learning experiences (PLEs); 20 observations and 10 reports. Some of the students talked about completing five or more proformas at one time. The physical space of the box in the proforma limited the amount of writing the students undertook, which is in tension with the purpose of writing reflectively which entails more extended text. These logbooks were designed to be read by the placement staff and/or the college tutor and then discussed with the student. All 
the project students reported that this discussion happened infrequently and, when it did, it covered a number of proformas at one time. One of the students commented that: 'I don't think she reads them really. She just signs them.' It seemed to the students that these documents served no real purpose. Many found them repetitive and did not use them for reflection but rather as a reference to tick off which aspect of the curriculum they had covered. Students often repeated similar phrases each week. One student wrote in over half of her PLE's 'I think my organizational skills could be improved.' She did not refer to her previous notes citing this as a problem, nor did she reflect on how this could be improved.

One important aspect of the placement for students was child observations. One English student disliked these more than any other aspect of the course, describing them as 'boring'. It became clear that what she found boring was not observing the child, but writing up the observation. She said: 'You have to do twenty and it takes ages to write them up.' This is a case of the literacy practice becoming a demand on top of the task itself. On the whole students did not use the logbook as a reflective tool. They used it to $\log$ events as they happened and to check they had completed all the tasks expected of them in the placement. A reflective logbook requires students to engage with a new set of literacy practices with which they were not familiar. Staff wanted the students to be more reflective and they commented on the entries lacking a reflective quality, but there seemed to be little if any explicit understanding of the literacy practices entailed in writing reflective documents and the need for that writing to be meaningful for the students. 


\section{Concluding remarks}

In terms of comparison, when exploring literacies for learning, there would appear to be more similarities than differences in the Childcare curricula in Scotland and England. What differences do emerge appear to be as much to do with the pedagogic stance of the tutor as any other factor (Miller and Satchwell 2006). Indeed the differences may be as significant within countries as between them, in particular in England where different awarding bodies, CACHE and Edexcel, provide different curriculum contexts within which to operate. At the level of literacy practices within the pedagogy of Childcare, country differences are not significant.

It is clear form the above that an integral aspect of learning careers are literacy careers. This is significant not simply for Childcare in further education, but for the curriculum as a whole. In relation to the vocational curriculum, it would seem logical for the students' literacy careers to develop into wider complexity as they progress. Starting with the more practical work-placed activities, more academic literacies would be gradually introduced on top of the developing practical and occupational literacies. However, we have found that students at the lower levels have to deal with many and varied literacy practices which may add an unnecessary level of complexity. In addition, their literacy practices within the classroom largely do not seem to prepare them for neither the workplace nor the next level of study. The implication is that new literacy practices introduced into the classroom need to be recognized as such, and that their potential relevance to the students' futures should be considered. Here there can be a tension in the literacy 
practices to be developed, given the dual purpose of the curriculum to both prepare the student for the workplace and/or for educational progression.

From the data, we note two tensions in the literacy of assessment. A general observation is that the literacy practices associated with the production of assignments at English level 3/Scottish HNC appear to be less related to those required in the workplace. There are two elements to this point. First, there is a tension between educational imperatives and occupational imperatives in terms of literacy practices, types of texts and types of engagement with texts required by students, especially as they progress in terms of level. What is required for educational progression and what for the workplace may differ and this difference is reflected in assessments. So the policy prioritises certain academic literacy demands rather than the workplace, even as it ostensibly positions employability and the workplace as a central concern. There are tensions here within educational policy. Second, there is the issue of interest and relevance. An assignment may be intended to be more interesting, as in writing an article for a magazine, but its relevance to the students may not be apparent. Higher level courses require writing essays, reports, letters, and other extended written documents. Without a fuller understanding of exactly what would be required in the workplace, it is difficult to say how relevant these activities are, of course. There is the argument that Education should offer more than that which is necessary for the workplace.

This raises the most fundamental of questions. Is the purpose of the programme to extend education or to fit vocational context? Each has implications for the literacy practices in 
which people participate, both students and tutors. If it is to do both, then the issues of what is valued as literacy and the resources necessary for the multimodality of the world will need seriously to be addressed in the curriculum expectations and pedagogic practices of Childcare courses. An extension of this is the debate in Childcare around practice and professional development. Many of the tutors felt that the programmes they were providing were about development of practitioners, yet the changes being made at policy level are focused on the idea of developing the professional role of the students. Our research shows that the students and the tutors respond well to the curriculum being enacted so that the connections to the workplace and their academic development are made more explicit through thinking in more detail about the different aspects of any given literacy practice.

At the broader conceptual level, this study points to the centrality of the semiotic practices to the learning careers of students, and that greater pedagogical consideration of their literacy careers, the forms of literacy practices required, formed and scaffolded, could enhance their learning. While the general discourses of policy and practice focus on students' deficits in literacy, exploration of Childcare students' everyday practices indicates it is the multiplicity and abundance of literacy practices which is an issue, when compared with the very specific sets of practices that are valued within the context of further education. Literacies for learning are fostered not simply by focusing on the development of individual skills, but by increasing the meaningfulness of tasks to students, taking into account that many students are still exploring what they might do as well as seeking preparation and qualifications in a certain vocational or subject area. 


\section{Notes}

1. This article arises from work done within the Literacies for Learning in Further Education research project, funded by the ESRC's Teaching and Learning Research Programme (grant number RES-139-25-0117 ).

2. Different names were used across the colleges: Faculty; School but for this paper we will refer to Department.

3. Descriptors are documents which are produced by the qualifications authority.

Depending on which authority they describe the learning outcomes and the assessments for particular units of study.

\section{References}

BARTON, D. and HAMILTON, M. (1998) Local Literacies: Reading and Writing in One Community (London,. Routledge).

BARTON, D.; HAMILTON, M. and IVANIC, R. (eds) (2000): Situated Literacies:

Reading and Writing in Context (London, Routledge).

BLOOMER, M. (1997) Curriculum Making in Post-16 Education (London, Routledge). CANNING, R. (2007) Reconceptualising core skills, Journal of Education and Work, 20, pp. 17-26.

COLLEY, H.; JAMES, D.; TEDDER, M. and DIMENT, K. (2003) Learning as becoming in vocational education and training: class, gender and the role of vocational habitus, Journal of Vocational Education and Training, 55, pp. 471-498. 
EDWARDS, R. and SMITH, J. (2005) Swamping and spoonfeeding: literacies for learning in further education, Journal of Vocational Education and Training, 57, pp. 4760.

GEE, J. (2003) What Video Games Have to Teach Us About Learning and Literacy (London, Palgrave).

KRESS, G. (2003) Literacy in the New Media Age (London, Routledge).

LANKSHEAR, C. and KNOBEL, M. (2003) New Literacies: Changing Knowledge and Classroom Learning (Buckingham, Open University Press).

LAVE, J. and WENGER, E. (1991) Situated Learning (Cambridge, Cambridge University Press).

Luckin, R., CONNOLLY, D., PLOWMAN, L., AIREY, S. (2003) With a little help from my friends: children's interactions with interactive toy technology, Journal of ComputerAssisted Learning 19, pp. 165-176.

MILLER, K. and SATCHWELL, C. (2006) The effect of beliefs about literacy on teacher and student expectations: a Further Education perspective, Journal of Vocational Education and Training, 58, pp. 135-150

PLOWMAN, L. and STEPHEN, C. (2005) Children, play and computers in pre-school education, British Journal of Educational Technology 36, pp. 145-158. 